\title{
EDUCATION
}

\section{Identifying Factors that Influence Student Success in Clinical Laboratory Sciences Program}

\section{PAYMAN NASR, CHERYL JACKSON-HARRIS}

\begin{abstract}
The profile of today's college students looks quite different than it did decades ago, when the average student was a recent high school graduate moving directly from high school to university. Students today are older, work to support themselves and their families, and are ethnically more diverse than their peers of decades past. The student demographic shifts necessitate regular evaluation of academic programs including reevaluating admissions requirements, financial aids availability, and schedule flexibility to meet the demands of the new student demographics. Clinical Laboratory Sciences (CLS) at California State University Dominguez Hills (CSUDH) is the largest CLS program in Southern California and is accredited by National Accrediting Agency for Clinical Laboratory Sciences (NAACLS). The program admits both undergraduate and post-baccalaureate candidates for training as Clinical Laboratory Scientists for careers in healthcare or research. Despite the great success in graduating well qualified candidates, there has been a trend in which a larger portion of students spend more time than expected to complete the program requirements. This phenomenon prompted the faculty at CSUDH to seek the causes for such lengthening time towards graduation. In the current study, we report the results of survey questionnaire that was submitted to CLS students at CSUDH in 2015. The results confirm the recent shift in student demographics in the CLS program and identify the primary obstacle towards a timely graduation to be inability to register for required courses due to schedule conflicts and/or intense competition for available seats.
\end{abstract}

\section{ABBREVIATIONS: CLS - Clinical Laboratory Sciences, CSUDH- California State University Dominguez Hills}

INDEX TERMS: Clinical Laboratory Sciences, Education, Student Demographics

Clin Lab Sci 2016;29(4):212-218
Payman Nasr, PhD, ASCP, Department of Clinical Laboratory Sciences, California State University Dominguez Hills, Carson, CA

Cheryl Jackson Harris, MS MLS, ASCP, Department of Clinical Laboratory Sciences, California State University Dominguez Hills, Carson, $C A$

Address for Correspondence: Payman Nasr, PhD, ASCP, Department of Clinical Laboratory Sciences, California State University Dominguez Hills, Carson, CA 90747, 310-243-3082,pnasr@csudh.edu

\section{INTRODUCTION}

The changing profile of our nation's college population represents progress toward giving more opportunities to the public to reach successful careers, regardless of backgrounds, ethnicities, or socioeconomic circumstances. Thus, it is essential to closely monitor such changes and act accordingly to adapt the current academic programs to meet the needs of the new student demographics we serve. CSUDH is a highly diverse, urban university located in the South Bay California primarily serving the Los Angeles metropolitan area and is considered one of the most ethnically-diverse universities in the United States with a student population that is 54.5 percent Hispanic/Latino; 17.7 percent Black/African American, 12.9 percent White, 11.4 percent Asian or Pacific Islander, 0.3 percent American Indian, and 3.2 percent two or more races. CSUDH ranks 33rd in the nation for the number of bachelor's degrees and 8th for the number of liberal arts degrees awarded to Hispanic students. In addition, the university ranks first in California for the number of bachelor's degrees awarded to African American students. In 2015, 61.9\% of students at CSUDH were females and the university had a larger than national average population of first-generation college students. ${ }^{1,2}$

Many current curricular norms are based largely on samples of "traditional students", who are 


\section{EDUCATION}

undergraduate college students moving directly from high school to four-year academic institutions full-time, live on campus, do not work, and have few, if any, family responsibilities. ${ }^{3,4}$ However, today's college students are increasingly splitting time among class, work and family obligations, and if there was ever a time when we needed a comprehensive understanding of the impact of student demographics on their academic success, it is now. It is important to note that investigative approaches that only try to focus on the influence of a few variables for all students will likely miss the key factors and provide little useful evidence for setting new practices and developing relevant guidelines. Therefore, routine evaluation of student demographics may provide possibilities in which to consider discontinuing, reevaluating and/or updating academic activities in favor of strengthening priority areas. Given this, it's imperative to provide the necessarily tools needed for the new student population in order to pave the path towards earning degrees and credentials, while maintaining a high standard for quality of professional programs. This could include embracing approaches such as using technology to make programs more widely accessible and offering course schedule flexibility to meet the demands of the students. The growing diversity of the undergraduate student body in American postsecondary education has been well documented over an extended period of time. ${ }^{5}$ One needs to only examine the 2015 U.S. Department of Education's National Center for Education Statistics to get a feel for this diversity and changing demographics from decades ago. For example, from 2013 to 2014, graduation rates for historically disadvantaged groups of students-including low-income students, minorities, and English-language learners-have increased by at least 3\%. In addition, the average yearly costs of education continue to increase around the country, and more and more students have to work while attending school to their needs. Previous reports have indicated working more than 20 hours a week contributes to a higher likelihood that students will drop out of school before receiving a degree. ${ }^{7}$ Fulltime workers are $10 \%$ less likely to eventually receive a degree than part-time workers or those who do not work at all. ${ }^{8,9}$ In addition, adult students 25 and over have an increasing presence on U.S. campuses, and this group of students comes to school with their own unique concerns and goals. ${ }^{10}$ According to a 2011 report from the Institute for Women's Policy Research (IWPR), there are nearly 4 million student parents currently enrolled as undergraduates in U.S. colleges and universities; this represents roughly one-quarter of all undergraduates. ${ }^{11}$ The current advances in information technology are also rapidly changing the requirements for a successful academic program and forcing serious reconsideration of our previous practices as how, when, and where instruction can be delivered and learning promoted. The research questions, designs, and methodologies on which we have relied in the past will not be adequate in the future because the previous research has assumed a general homogeneity in the educational process and student demographics. Taken together, overwhelming evidence supports the shift in college student demographics and highlights the need for an in depth assessment of the new student demographics in order to address the concerning issues. Therefore, it is necessary to regularly monitor the student population and develop new designs and methods that meet the needs of the new student population. In light of such realities, understanding characteristics and preferences of the new generations of students is the first step in optimizing current academic training programs; however, there has been little investment in methodologic research in order to address the key needs and demands of the current student population.

Learning is a dynamic process that has to adapt to changing academic landscape and particular needs of each student population. Consequently, it is critical for the faculty to develop and put into practice innovative approaches that target the exact need of each unique student population to ensure student success. Early identification and addressing of such issues may allow the implementation of rapid interventions in order to lessen the impact of such factors on student academic success. It seems apparent the ways we provide instruction, finance education, and measure student learning have not changed over years. ${ }^{3}$ The rapid advances in medical sciences and information technology are changing the relationship between the profession and academic training. ${ }^{12,13}$ This trend is accelerating and requires many professional programs such as clinical laboratory sciences to adapt new curricular approaches in order to remain relevant to the profession. In this atmosphere, enabling students to reach their optimal academic potential regardless of their background and personal lives is a difficult task. Here, we report and discuss the results of a recent survey that was submitted to part-time and fulltime students who have declared their major as the 
Clinical Laboratory Sciences at CSUDH. The primary goal of this study was to identify the major obstacles on CLS students' path towards a timely graduation from the students' perspective.

\section{MATERIALS AND METHODS}

All experimental protocols were reviewed by the Institutional Review Board at CSUDH, receiving an exemption from the requirements of 45-CFR-46 according to exempt category 2 concerning research involving the use of educational tests (cognitive, diagnostics, aptitude achievement), survey procedures, interview procedures or observation of public behavior. The Bachelor of Science degree and the post baccalaureate certificate program options in Clinical Science at CSUDH are designed to provide academic and clinical routes to professional certification and California state licensure baccalaureate level preparation in the clinical science professions. An average of 44 students complete the CLS program at CSUDH per year with $99.5 \%$ certification rate by American Society of Clinical Pathology (ASCP), Board of Certification (BOC) and California State Department of Public Health. Upon the completion of the program requirements and successful certification examination(s), the students are considered to be health professionals armed with the technical skills and knowledge theory necessary to meet current and future standards of quality laboratory and healthcare services practice.

Two surveys were conducted during the study. The first survey was an online questionnaire that was emailed to all part-time and full-time CLS students who declared their major as Clinical Laboratory Sciences $(n=220)$ in spring 2015. The questionnaire included 13 questions ranging from multiple choices to rating scales to open comments. The questionnaire was administered to students from various levels of advancement (i.e., freshmen / seniors / post-baccalaureates) with the main focus being to identify the contributing factors that may interfere with student progress in the CLS program from the students' perspective. The second survey was only submitted to the students who had successfully entered the internship program with the main goal being to establish the strengths and weaknesses of the CLS program from the students' perspective who are about to complete the program requirement and earn their certification. The questionnaire format for the second survey was similar to that of the first survey but consisted of 10 multiple choices, rating scales, and open comment questions. The participation in both surveys was anonymous and voluntary, and there were no penalties against those who declined participating in the study. For the online survey, the students received three reminders one week apart in which the principle investigator restates the request for their participation in the survey. Four weeks following the original contact, the data was collected, analyzed, and salient features are presented in this report.

\section{RESULTS}

\section{Student Demographics}

A questionnaire was emailed to 220 freshmen, sophomore, junior, seniors and post-baccalaureate students in Clinical Laboratory Sciences program. There were a total of 61 responses (27.7\%). A large proportion of students who responded to the survey were postbaccalaureate students ( $13 \%)$ followed by junior/seniors and freshmen/sophomore (Table 1). $71.4 \%$ of students were full-time students, while the remaining students were part-time, recently graduated or changed major. The top four ethnicities among CLS students were: Asian at $66.3 \%$, Latino/Hispanic at 20.2 $\%$, White at $7.0 \%$, and African American $4.5 \%$. Almost $40 \%$ of students were working more than 20 hours per week, and $45 \%$ of students commuted 20 or more miles each way to school (Table 1).

\begin{tabular}{ll}
\hline Table 1: Student demographics. & \\
\hline Academic Standing & Percent Total \\
Freshman / Sophomore & 5.36 \\
Junior / Senior & 12.50 \\
Post-Baccalaureate & 81.4 \\
Full-Time & 71.43 \\
Part-Time & 28.57 \\
Ethnicity & \\
Asian & 66.3 \\
Hispanic / Latino & 20.2 \\
White & 7.0 \\
African American & 4.5 \\
Employment (hours per week) & \\
$0-10$ & 45.45 \\
$10-20$ & 14.55 \\
$20-30$ & 10.91 \\
$30+$ & 29.09 \\
Commute to School One Way (miles) & \\
$0-10$ & 20 \\
$10-20$ & 36.36 \\
$20-40$ & 32.73 \\
$40+$ & 10.91 \\
\hline
\end{tabular}




\section{Student Perception}

Approximately $42.3 \%$ of students were of the opinion that the primary factor which will most effectively facilitate their academic success rate to be course accessibility, while others stated more frequent advising (19.2\%), better study habits (12.7\%), financial support (6.4\%), and improved faculty/students relationship $(19.2 \%)$ as the key facilitators of academic success. When the students were asked to identify the factors that are most influential in their timely graduation, the majority $(70.2 \%)$ stated the ability to register for courses they need as the most influential followed by better advising $(8.5 \%)$, better management of outside employment and financial needs $(8.5 \%)$, better study habits $(6.4 \%)$, and better interaction with faculty $(6.4 \%)$. More than $74 \%$ of the respondents indicated that the most significant obstacle on their path towards timely graduation to be challenges associated with course registration due to schedule conflicts and/or intense competition for available seats, while $17.31 \%, 3.85 \%, 1.92 \%$ stated the financial needs, course difficulty, and better advising as the main obstacle, respectively. More than $52.9 \%$ of students identified course accessibility and availability as the key factor for improving the CLS students' success rate (Table 2).

\begin{tabular}{ll}
\hline Table 2: Survey questionnaire responses. & \\
\hline Primary obstacles towards graduation & Percent Total \\
Curriculum difficulty & 3.85 \\
Ability to register for necessary courses & 76.92 \\
Financial needs & 17.31 \\
Advising & 1.92 \\
Factors most likely affecting academic success & \\
Course accessibility & 42.55 \\
Advising & 19.15 \\
Less work / financial needs & 6.35 \\
Faculty accessibility & 19.15 \\
Better study habits & 12.77 \\
Factors most likely influencing a & \\
graduation & \\
Course accessibility & \\
Advising & 70.21 \\
Work / Finances & 8.51 \\
Better faculty-student relationship & 8.51 \\
Better study habits & 6.38 \\
How to improve student success rate & 6.38 \\
Course accessibility & \\
More internship opportunities & 52.94 \\
Lowering the requirements & 20.59 \\
More frequent advising & 5.88 \\
\hline
\end{tabular}

\section{Program Strengths and Weaknesses}

When the students in clinical internship were asked about the strengths and weaknesses of the CLS program, $57 \%$ of the respondents indicated the greatest strength of the program to be the quality of internship (ranked 1), followed by the quality of faculty and the course work. More than $88 \%$ (ranked 1) of students considered difficulties with course registration and access to required classes as the greatest weakness in the program followed by problems associated with the advisor /student ratio (Table 3).

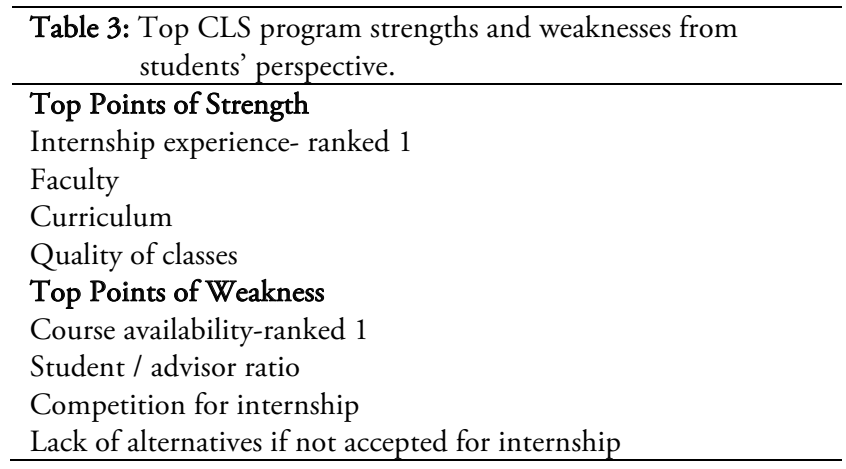

\section{DISCUSSION}

Higher education in the United States is at a critical juncture as many universities and colleges struggle to develop strategies and methodologies to better prepare students for careers in the $21^{\text {st }}$ century. Considering the rapid change in the academic landscape and student demographics, educators are well aware of the significant changes needed in their approaches in preparing students for career in their field of interest, ${ }^{13,14}$ Hence, in order to better prepare students for their professional career, we need to regularly monitor the student population to better understand who they are.

The Bachelor of Science Degree in Clinical Laboratory Sciences provides an academic and clinical route to professional credentials, allowing the graduates, upon passage of the appropriate certification examination(s), to become health professionals armed with the knowledge base and technical skills required for CLS profession. Currently, the CLS program at CSUDH consists of two components: a didactic component and a clinical training component. The mission of the didactic component is to prepare clinical laboratory scientists with the technical and critical thinking as well as management skills in order to allow them functioning at the highest professional level in both clinical laboratory and research settings, assuming leadership roles in their working environment, and becoming leaders in their 


\section{EDUCATION}

field of interest. The clinical component of the CLS program is offered under the supervision of university faculties, in affiliation with clinical instructors employed by the state approved and accredited diagnostic health care facilities with emphasis on technical hands-on training in laboratory skills in an actual healthcare related facility.

In this report, we have described the results of anonymous surveys that were submitted to CLS students at CSUDH, which has one of the strongest CLS programs in California. The survey findings indicated two general issues: On the side of students, the survey identified several contributing factors that are believed by the students to be the primary obstacles towards a timely graduation. The most important of these obstacles were inability to register for required course work due to schedule conflicts and/or intense competition for the available seats. On the side of faculty, it appears to be a need for innovative instructional approaches to improve students' resource access and learning experience.

The challenge with registration for the required courses is a multifaceted problem. On one hand, there is competition for seats in high demanding courses which often have both lecture and laboratory components. Since laboratory components will always carry a maximum student enrollment cap, the numbers of students who can register in these courses are limited. On the other hand, students need these courses to fulfill the program requirements and advance in the program. This issue can be addressed by multiple tactics. One approach is to increase course laboratory sections which require more class space, more faculties, and more resources; however, the continuous budget cuts in education have made this solution often financially out of reach for many academic institutions. Another approach is to increase the frequency of course offerings throughout the year (spring, fall and summer courses). This approach may reduce the back log of students who are waiting to fulfill the program requirements but still require additional resources and funding. Another approach may be to accept the transferred credits for high demand courses from other academic institutions. This step may allow students to take the needed course in other accredited institutions and transfer the units to their institution of interest, in turn preventing any delay on the path towards graduation. Additional approaches to address this issue may be the prioritization of student registration based on the seniority level (i.e. post-baccalaureate $>$ seniors $>$ juniors $>$ sophomores $>$ freshmen), in the process allowing the more advanced students to have priority over the novice students.

The high rate of employment among students expresses the need for a wider access to student financial aid. The faculty and staff may assist in this approach by seeking sources for grants and scholarship to allocate to students who excel in their field of interest. Other approaches may include better financial orientation for prospective students in order to identify intervention opportunities to better educate students and their families about the college cost and prudent means of paying it off. However, the most fundamental approach should involve the government support and policymakers attention in order to ensure that resources to help cover college's cost, such as tax credits, grants and loans, reach students with the greatest need. In addition, to create incentives for students to graduate in a timely fashion, universities may reward those who actually complete their degrees on time by lowering student loan interest rate or partial debt forgiveness, in the process lessening the financial burden on students and encouraging them to graduate as promptly as possible.

Recent advancement in computers and information technology has shifted the face of academic institutions. ${ }^{15}$ Such technologies have significantly enlarged the range of options for academicians to improve the prospects of a more efficient academic setting that is beneficial to all students and simple to follow. One reasonable approach is to develop new computer programs that automatically monitor student progress. ${ }^{16}$ Such compass programs can be used to match the students' major's with available courses, avoid schedule conflicts, give priorities to more senior students to enroll in the courses, and most importantly, give a clear perspective of the road towards program completion. Providing access to an automated compass platform will allow students to keep track of their own overall progress towards degree completion and provide them with early warnings regarding the conflicts which may ensue. Perhaps as a feature of this technology, upon missing milestones, the students, the advisors, and the program directors will be automatically notified via warning emails and notifications.

Finally, the faculty should utilize a prudent combination of technology and didactic approaches to enhance the 
students' learning experience while maintaining a high quality program. That may require the faculty to measure student learning experience and not just simply classroom time. At the present, students' readiness is assessed by time spent in the classroom rather than the learning that is achieved. New advanced technological methods can be utilized to allow students to complete part of their education without being present in a classroom. For instance, part of the course material can be allocated to online activities that can be done at the students' convenience. For instance, some laboratory practices may be reinforced with online exercises, in turn reducing the number of in person classroom contact hours and giving students more autonomy in managing their own schedule. This may also allow students to better manage their obligations regarding employment and family matters. Perhaps a prudent augmentation of technology into the traditional classroom may accomplish this task without compromising the quality of student training. Of course, one must not discredit the role of faculty to facilitate the learning process using modern technologies. A new technology is only an effective tool in teaching if it is presented in concert with the appropriate instructional guidelines. Teachers who decide to implement new technologies in their classrooms should recognize that such technologies, if not introduced with the appropriate training, might be very time-consuming and frustrating. However, a short period of training on the application of available technologies at the beginning of each course will ensure the success of students in utilizing the technologies effectively. The resulting schedule flexibility permits students to review the material according to their own personal schedule without the stress of other factors in their environment. This advantage is particularly apparent among the student population who holds outside employment, has family responsibility, and commutes long distances to get to school.

In conclusion, the current report highlights the effort of the faculty at CSUDH to assess the student demographics in order to find innovative ways to improve and enhance the students' learning experience in respect to the gradual shift in the student demographics. Utilizing a multifaceted approach to this enormous task enables faculty to broaden the horizon of the learning experience in a professional program setting, while encouraging the students to become more actively involved in their own education with less time constraints. This higher level of learning experiences is a necessary footstep into the ever-changing workforce and appears an essential step to meet the intense curricular demands that are expected from students in the $21^{\text {st }}$ century.

\section{ACKNOWLEDGEMENT}

This study was possible by a grant support from Institutional Effectiveness Assessment at California State University Dominguez Hills.

\section{REFERENCES}

1. Zinshteyn M. How to Help First-Generation Students Succeed. http://www.theatlantic.com/education/archive/2016/03/howto-help-first-generation-students-succeed/473502/.The Atlantic. Mar 13, 2016.

2. California State University Dominguez website. http://www4.csudh.edu/ir/enrollment/ethnicity/index

3. Changing Times In Teacher Education: Restructuring Or Reconceptualising? Routledge; 2013. https://books.google.com/ books?id=am7tNUXvmWYC\&pgis=1.

4. Hainline L, Gaines M, Feather CL, Padilla E and Terry E. Changing Students, Faculty, and Institutions in the TwentyFirst Century. Peer Rev. 2010;12(3). https://www.aacu.org/ publications-research/periodicals/changing-students-facultyand-institutions-twenty-first-century.

5. Common Core of Data (CCD). http://nces.ed.gov/ccd/data tables.asp.

6 Graduation Gap Between White, Minority Students is Narrowing, But Persistent - Politics K-12 - Education Week. http://blogs.edweek.org/edweek/campaign-k-12/2015/03/grad uation_gap_between_white_m.html.

7. Karatas S. The Effect Of Working On Academic Success And Social Lives Of University Students. Int J Soc Sci Educ. 2014;5(1):1-15. http://ijsse.com/sites/default/files/issues/2014/ v4-i5-2014/Paper-18.pdf.

8. Orszag JM, Orszag PR and Whitmore DM. Learning and Earning: Working in College. Upromise, Inc. N.p,

9. Most Students Over Age 25 | Rankings | US News Best Colleges. http://colleges.usnews.rankingsandreviews.com/best-colleges/ rankings/most-over-25.

10. College Students with Children Need Campuses with Child Care | FemChat. http://www.iwpr.org/blog/2011/05/03/ college-students-with-children-need-campuses-with-child-care/.

11. Christenbury L. The flexible teacher. Eff Educ. 2011;68(4):4650. http://www.ascd.org/publications/educational-leadership/ dec10/vol68/num04/The-Flexible-Teacher.aspx.

12. Cox MD and Richlin L. Emerging Trends in College Teaching for the 21st Century. J Excell Coll Teach. 1993;4:1-7.

13. Christensen R. Effects of Technology Integration Education on the Attitudes of Teachers and Students. J Res Technol Educ. 2002;34(4):411-33. doi:10.1080/15391523.2002.10782359.

14. Mouza C. Learning to Teach with New Technology. J Res Technol Educ. 2002;35(2):272-89. doi:10.1080/15391523. 2002.10782386.

15. Rogers DL. A Paradigm Shift: Technology Integration for Higher Education in the New Millennium. AACE J. 
2000;1(13):19-33./p/8058/.

16. Siegfried RM, Wittenstein AM, Sharma T. An automated advising system for course selection and scheduling. J Comput
Sci Coll. 2003;18(3):17-25. http://dl.acm.org/citation.cfm?id $=771712.771718$.

\section{Don't Miss the Spring 2017 Series by Outstanding Lab Experts!}

\section{ASCLS members - register with special DISEOUNT BODE for a reduced site rate!}

Visit www.ascls.org/webinars for details

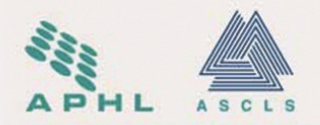

APHL-ASCLS Webinar Series

www.aphl.org/webinars 